\title{
Microsoft Onenote como objeto de aprendizagem: estudo de caso de como docentes podem utilizar instrumentos virtuais nas mediações sociais contemporâneas de ensino
}

\author{
Gilberto Balbela Consoni ${ }^{1}$, Letícia Angheben el Ammar Consoni ${ }^{2}$ \\ ${ }^{1}$ Colegiado de Design Gráfico e Digital - Universidade Federal de Pelotas (UFPel) \\ Pelotas - RS - Brasil \\ ${ }^{2}$ Programa de Pós-Graduação em Comunicação e Informação da Universidade \\ Federal do Rio Grande do Sul (PPGCOM/UFRGS) \\ Porto Alegre - RS - Brasil \\ gilberto.consoni@ufpel.edu.br, le.angheben@gmail.com
}

\begin{abstract}
This paper investigate how the professionals involved with learning may use Learning Objects in the contemporary social mediation on teaching. The text main goal is to define didactically Learning Objects to apply it on learning through the Microsoft OneNote tool. The methodology used to the empiric research was the case study of the tool application as a notebook at classroom of the Information Design course at Federal University of Pelotas. The study case dealt with the production through the content analysis which had been published by professor and it dealt with the reception through the students whom had used the tool during 2016.

Resumo. O presente artigo investiga como profissionais envolvidos com a docência podem utilizar Objetos de Aprendizagem nas mediações sociais contemporâneas de ensino. $O$ objetivo principal do texto é definir didaticamente Objetos de Aprendizagem para aplicação no ensino por meio da ferramenta Microsoft OneNote. A metodologia utilizada para a pesquisa empírica foi o estudo de caso do uso do aplicativo como bloco de anotações na sala de aula da disciplina de Design da Informação da Universidade Federal de Pelotas. O caso tratou da produção por parte da análise dos conteúdos disponibilizados pelo professor e da recepção por parte dos alunos que utilizaram a ferramenta durante 2016.
\end{abstract}

\section{Introdução}

A inserção de tecnologias digitais nas mediações sociais contemporâneas tem causado rupturas sociais, culturais e econômicas no exercício das atividades docentes ao adicionar-se ferramentas digitais no ensino, antes exclusivas a um pequeno espectro de profissionais, como os da computação e da informação. No âmbito social, ao se considerar as questões que envolvem a inclusão e a alfabetização digital funcional, os professores ou os alunos não capacitados a produzirem e a consumirem conteúdos mediados por computador, estarão inaptos a estenderem o aprendizado além da sala de aula presencial. Com relação ao eixo cultural, o acesso à informação por meio de instrumentos educacionais através da informática permite aos professores e aos alunos expandirem o horizonte de aprendizado à distintas culturas, o que antes era exclusividade de leitores assíduos ou de viajantes que podiam arcar com altos custos para conhecerem outros lugares. Já no campo econômico, a inserção de instrumentos assistidos pela informática está além das potencialidades de reutilização de materiais digitais e da difusão de conteúdos de ensino, pois pode até mesmo causar diminuição no quadro de professores das instituições de ensino, ao provocar turmas com excessivo número de alunos nos ambientes de ensino à distância. Como pode ser observado, a 
emergente capacitação de professores em instrumentos digitais de ensino é uma problemática contemporânea a ser tratada científica e aplicadamente pelas rupturas causadas nesses três campos. O presente artigo investiga como profissionais envolvidos com a docência podem utilizar objetos de aprendizagem (OA) nas mediações sociais contemporâneas de ensino. A partir do resultado da pesquisa, o objetivo principal do texto é definir didaticamente OA para aplicação no ensino por meio da ferramenta Microsoft OneNote. A metodologia empregada utilizou como técnicas a pesquisa bibliográfica, para definir OA; e o estudo de caso do uso da ferramenta OneNote como objeto de aprendizagem reutilizável na disciplina de Design de Informação da Universidade Federal de Pelotas no ano de 2016, para analisar a experimentação deste instrumento de ensino em uma amostra real de pesquisa.

\section{Definição de Objetos de Aprendizagem}

A reflexão do tema $\mathrm{OA}$ foi ampliada com a emergente informática na educação e com o aumento do uso de tecnologias instrucionais para apoiar o ensino. Por ser um tema em constante desenvolvimento, encontra-se na literatura especializada múltiplas definições, como a de Wiley, segundo a qual podem ser delimitados como OA "qualquer recurso digital que pode ser reutilizado para apoiar a aprendizagem" $(2000, \text { p. } 7 \text {, tradução nossa })^{1}$. Ao fazer uma análise crítica das pesquisas recentes sobre o tema, os autores Galafassi, Gluz e Galafassi (2013) seguem essa definição: “OA é uma espécie de 'porção' reutilizável de conteúdo educacional. Qualquer entidade digital ou não digital, que possa ser usada, reusada e referenciada com tecnologia no suporte ao aprendizado".

Por um lado, a conceituação defendida por Wiley está baseada na definição do Learning Technology Standards Committee (LTSC) do Institute of Electrical and Electronics Engineers (IEEE), responsável por apontar padrões que assegurem a interoperabilidade ${ }^{2}$ das tecnologias instrucionais. Por outro lado, diferencia-se da mesma em um ponto crucial: OA são entidades digitais e tão somente assim podem conter todas as características que o definem como tal. Ainda que a definição do autor seja uma das mais populares, o pesquisador Polsani acredita que a mesma mantém os OA em um patamar amplo, empregada por vezes sem critério, ao se tornar um mero slogan (POLSANI, 2003). Para o crítico, o que existe é uma carência de conceitos claros e reflexões combinadas com uma multiplicidade de definições, o que resulta no uso ordinário do termo.

Para Polsani, uma definição precisa trazer propriedades suficientemente bem definidas para que o conceito possa ter validade em qualquer contexto e nunca estar baseado, no que ele chama, de considerações subjetivas. Observa-se que o trabalho de Wiley vai além da significação precisa a respeito de OA. Salienta-se que o estudo do autor apresenta atributos críticos que definem os $\mathrm{OA}$ ao fazer profundas reflexões sobre o tema. No livro The Instructional Use of Learning Objects ${ }^{3}$, Wiley simplifica uma complexa definição em objetivas palavras, ao chamar a atenção à reflexão maior entorno da aprendizagem através do computador e à utilização pedagógica dos recursos digitais. Por um lado, minimiza o conceito, mas por outro estende a reflexão.

Ao acompanhar o desenvolvimento de tecnologias instrucionais que se destacam ao ganhar cada vez mais espaço na dinâmica da sala de aula, outras definições surgiram no Brasil. Destaca-se neste cenário o projeto da extinta Secretaria de Educação à Distância, do

\footnotetext{
${ }^{1}$ Tradução nossa: "Any digital resource that can be reused to support learning” (WILEY, 2010, p.7)

${ }^{2} \mathrm{~A}$ interoperabilidade dos componentes digitais refere-se à capacidade de funcionamento em diferentes plataformas.

${ }^{3}$ Wiley, D. A. (Ed.). The Instructional Use of Learning Objects: online version. 2000. Disponível em: http://reusability.org/read/chapters/wiley.doc Acesso em: 13 set. 2016
} 
V Congresso Brasileiro de Informática na Educação (CBIE 2016)

Anais do XXII Workshop de Informática na Escola (WIE 2016)

Ministério da Educação, chamado Rede Interativa Virtual de Educação (RIVED). No final da década de noventa, o projeto iniciou trabalhos voltados para a capacitação de docentes no uso e na produção de OA. Semelhante à do LTSC, a definição estabelecida pelo RIVED para OA considera-os como: “[...] qualquer recurso que possa ser reutilizado para dar suporte ao aprendizado. Sua principal ideia é 'quebrar' o conteúdo educacional disciplinar em pequenos trechos que podem ser reutilizados em vários ambientes de aprendizagem" (REDE INTERATIVA VIRTUAL DE EDUCAÇÃO, 2011).

A crítica de Polsani também se sobrepõe a esta definição por sua superficialidade em definir quaisquer recursos como objetos de aprendizagem desde que tenham um propósito educacional. Ao definir qualquer conteúdo educativo na web como OA, o próprio estudo do tema perde o sentido, dada a abordagem panorâmica (ECO, 1998) que seria proporcionada sobre o mesmo. No entanto, assim como Wiley, a significação proposta pelo RIVED considera como fundamental o caráter reutilizável dos OA, menciona a quebra de conteúdo e remete à importância do fluxo de uso do material pedagógico em distintos ambientes de aprendizagem.

Os OA produzidos pelo RIVED ficavam disponíveis na própria página do órgão ${ }^{4}$, que funcionava como repositório de conteúdo digital reutilizável. Ainda na página, era possível obter informações institucionais relacionadas à criação do projeto que visava o incentivo no desenvolvimento da tecnologia para uso pedagógico. Com este objetivo em mente, o RIVED adotou alguns padrões para a elaboração, desenvolvimento e armazenamento dos OA. Dentre estes, destaca-se o Guia do Professor Rived, cujo documento apresentava sugestões de usabilidade dos objetos de aprendizagem ali depositados.

Ao investigar tecnologias relacionadas aos OA, encontra-se termos como recurso digital, reutilizável, aprendizagem e acessibilidade. No entanto, OA não são quaisquer recursos digitais, são apenas aqueles voltados para a educação, pensados e elaborados a partir de algum design instrucional em convergência com uma proposta pedagógica. $\mathrm{O}$ desenvolvimento de materiais baseados em informática na educação aprimora os ambientes virtuais de ensino. Por essa razão, não se pode considerar qualquer material pedagógico disperso na web como OA. Ademais, não se trata da simples transposição de práticas do presencial para o virtual, imposta pelas tecnologias de informação e de comunicação. Esta pesquisa trabalha objetos de aprendizagem como entidades pedagógicas virtuais, produzidos através de recursos digitais com características pré-estabelecidas, entre elas: reusabilidade, interoperabilidade, interatividade e acessibilidade, que serão abordadas mais a frente no presente texto. Antes, destacam-se as diferentes abordagens que definiram OA desde o seu surgimento e os principais pesquisadores e centros de pesquisa que investigam o tema.

\section{Requisitos funcionais de Objetos de Aprendizagem}

OA são recursos digitais utilizados de acordo com uma metodologia pedagógica no processo de educação e diferem-se dos instrumentos tradicionais pela virtualização dos recursos pedagógicos. Paralelo à incorporação das novas tecnologias de informação e comunicação ${ }^{5}$ na rotina dos professores, dos alunos e da sociedade de uma forma geral, estes recursos digitais permitem que "novas práticas ampliem antigas possibilidades" (BEHAR, TORRENZZAN e

\footnotetext{
${ }^{4} \mathrm{O}$ projeto foi descontinuado, mas a página continua disponível em http://rived.mec.gov.br/site_objeto_lis.php.

5 “Ao me referir a 'novas tecnologias de comunicação', considero os meios de comunicação digital que constituem o ciberespaço. A Internet é uma tecnologia que existe desde meados do século passado e já não pode ser considerada uma nova tecnologia, mas a web tem 20 anos e a nova forma como ela constitui o ciberespaço, permitindo novas formas de comunicação na contemporaneidade, é o que leva a caracterizá-la como uma nova tecnologia" (CONSONI, 2010, p. 13).
} 
V Congresso Brasileiro de Informática na Educação (CBIE 2016)

Anais do XXII Workshop de Informática na Escola (WIE 2016)

RÜCKERT, 2008, p. 2). Dessa forma, segundo Behar, Torrezzan e Rückert (2008, p. 2), estes recursos: "Surgem como uma ferramenta capaz de possibilitar a reestruturação de práticas pedagógicas, originando novos pensares a respeito do uso da comunicação, da ciência da informação da construção do conhecimento e a sua interação com a realidade".

As possibilidades de simulações, animações e representações são recursos atrativos para o uso deste material educacional, que proporciona ao aprendiz experiências que não poderiam ocorrer no presencial, como a realização de experimentos com produtos inflamáveis, uma viagem espacial, ou mesmo uma aula de anatomia onde todos os envolvidos podem, ao mesmo tempo, ter a mesma e privilegiada visão em 3D de um órgão ou aparelho. Aplicam-se neste cenário as potencialidades proporcionadas pela realidade aumentada. A utilização do OA coloca o estudante em contato com a informática na educação de uma forma prática e lúdica. Sabe-se que os instrumentos de ensino tradicionais podem fomentar a curiosidade, a descoberta de novas perspectivas sobre um tema e o desenvolvimento da representação do imaginário do aluno, contudo, quando bem estruturados os OA podem ampliar essas ações e transformar a relação entre o estudante e o conteúdo. De acordo com Prata, Nascimento e Pietrocola:

[...] OA no formato de atividades contendo animações e simulações têm se apresentado como possibilidades de desenvolvimento de processos interativos e cooperativos de ensino e aprendizagem, estimulando o raciocínio, novas habilidades, a criatividade, o pensamento reflexivo, a autonomia e autoria. (PRATA; NASCIMENTO; PIETROCOLA, 2007, p. 107)

Desse modo, estratégias pedagógicas, metodológicas e educacionais precisam atender as novas possibilidades, do presencial para o virtual, para que a experiência do aluno possa atingir o nível necessário ao seu aprendizado. O aproveitamento máximo desse recurso ocorre quando o objeto de aprendizagem possui requisitos funcionais como autonomia, interatividade, reusabilidade, acessibilidade, interoperabilidade e durabilidade. Tais características, conforme já apontado são essenciais à definição do conceito de OA, visto que sua inter-relação e complementaridade o distingue dos demais aplicativos, das páginas web e de imagens.

A autonomia de um objeto de aprendizagem diz respeito à sua capacidade de representar uma temática individual. Logo, o OA deve conter um conteúdo didático que tenha início, meio e fim e possa ser utilizado individualmente, sem estar por qualquer razão sujeito a uma plataforma ou ambiente virtual de aprendizagem. Em termos de conteúdo, a utilização do OA deve variar de acordo com a necessidade do professor. Mas, em relação ao seu desenvolvimento, a preocupação que se deve ter é de elaborar um conteúdo autônomo, que pode ser ou não combinado com outras estratégias pedagógicas.

Os OA mantêm uma relação de interatividade entre o conteúdo e o usuário, que pode agir de forma ativa em relação ao processo de ensino. A interatividade representa uma característica importante na relação do aluno com o conteúdo presente nos OA. Através da possibilidade de interferir e modificar a informação recebida, o aprendiz ganha autonomia na utilização das tecnologias (BEHAR, TORRENZZAN e RÜCKERT, 2008). Esta estrutura tecnológica faz com que alunos e professores possam interferir na apresentação de um conteúdo de diferentes formas, sem estarem condicionados necessariamente, à linearidade da informação, como em um livro didático. Essa não linearidade também se apresenta nas próprias trocas entre os interagentes envolvidos. Em um ambiente que permita troca de informação entre professor-aluno e aluno-aluno, as interações mais horizontalizadas podem contribuir, por exemplo, com a solução de uma dúvida a todos participantes do ambiente, destacando-se, muitas vezes, a não interferência do próprio professor que se apresenta como mediador ou até mesmo espectador. 
Observa-se que a hipertextualidade é um elemento característico da função de interatividade nos OA. Como o conteúdo apresenta-se divido em módulos independentes, o professor pode direcionar o seu uso de acordo com o seu plano de ensino, ou com a resposta dos alunos frente ao conteúdo. No que tange a organização do conteúdo, os OA são blocos de informação, construídos em pequenos conjuntos com o objetivo de maximizar as situações de aprendizado em que pode ser utilizado (TAROUCO, FABRE e TAMUSIUNAS, 2003).

A reusabilidade é uma das mais conhecidas características dos objetos de aprendizagem, já que é mencionada na maioria das definições que tratam do assunto. A reutilização de material educacional é um elemento de identificação indiscutível dos OA. No entanto, não se pode chamar de novo o reaproveitamento pelos professores de qualquer que seja o material didático. Segundo Wiley (2000), os professores sempre reutilizaram material educacional, por razões como a economia de tempo ou mesmo pela estática dos currículos. No entanto, a reusabilidade significa um dos elementos funcionais de maior destaque para os OA, pois está relacionada à capacidade de funcionar em diferentes contextos instrucionais (POLSANI, 2003). Portanto, para que o OA seja reutilizado, não basta que o professor ou um conjunto de professores o utilize várias vezes. É preciso que haja um formato reutilizável podendo ser executado em diferentes contextos de aprendizagem, sem modificações da sua estrutura e design. Conforme Pereira, Porto e Melo: "Ambientes diferentes implicam que um objeto de aprendizado pode ser usado em sistemas de gerência de aprendizado (learning management systems - LMS) ou sistemas de gerência de conteúdo de aprendizado (learning content management systems - LCMS) diferentes" (PEREIRA, PORTO e MELO, 2003).

Em relação à construção de $\mathrm{OA}$, a reusabilidade pode proporcionar certas vantagens de utilização como a economia de recursos humanos e financeiros. Dessa mesma forma, outros professores, tutores ou instrutores podem fazer uso de materiais já construídos, disponíveis em repositórios digitais. A reusabilidade envolve também uma troca de conhecimento e de esforços dos professores, designers, programadores e instituições ou consórcios de instituições que buscam um padrão de interoperabilidade dos OA. Conforme Behar et al, "Um mesmo objeto pode ter diferentes usos, seu conteúdo pode ser reestruturado, ou reagregado, e ainda ter sua interface modificada para ser adaptada a outros módulos" (BEHAR et al, 2009, p. 68). Com essa finalidade, os OA são descritos conforme padrões de metadados, utilizados para a catalogação e posterior recuperação através dos sistemas de busca específicos, o que permite a ampliação do seu uso. Os metadados de um OA tem por finalidade descrever suas características de forma a permitirem a sua posterior catalogação em repositórios digitais, podendo assim serem recuperados através de sistemas de busca (TAROUCO, FABRE e TAMUSIUNAS, 2003). Para que isso ocorra de forma satisfatória, durante a construção de OA utiliza-se um padrão de metadados com o objetivo de reunir os dados relevantes para a indexação e recuperação. Da mesma forma, conforme Tarouco, Fabre, Tamusiunas, é preciso buscar uma independência das plataformas onde os OA foram inicialmente pensados e elaborados:

A adoção de padrões abertos [...] é desejável uma vez que o rápido avanço da tecnologia leva à possível substituição de plataformas de gerenciamento de aprendizagem com maior rapidez do que a desatualização e ou obsolescência de um objeto educacional, que pode ser atualizado e continuar e ser reusado em outro contexto. (TAROUCO, FABRE e TAMUSIUNAS, 2003, p. 2)

O avanço tecnológico nesta área do conhecimento expande para além dos computadores, migra em direção às tecnologias portáteis como os computadores de mão, os telefones celulares e os tablets. Portanto, é importante que cada vez mais se pense a respeito dos fatores que são determinantes para a reutilização dos OA entre outras características. 
V Congresso Brasileiro de Informática na Educação (CBIE 2016)

Anais do XXII Workshop de Informática na Escola (WIE 2016)

Conforme já foi dito, a correta catalogação dos metadados, além de facilitar a reutilização, também possibilita uma melhora na acessibilidade e interoperabilidade desta tecnologia.

A acessibilidade é outro conceito característico dos $\mathrm{OA}$ que diz respeito à possibilidade de acesso dos recursos informacionais através da correta catalogação dos metadados e o seu armazenamento em repositórios específicos (POLSANI, 2003). Os OA devem ser acessíveis através das bases de dados especializados, porque isso significa que foram corretamente identificados e permite que sejam reutilizados. A acessibilidade também significa a possibilidade de acessar recursos educacionais em um local remoto e usá-los em outros locais (TAROUCO, FABRE e TAMUSIUNAS, 2003). Dessa forma, os requisitos funcionais dos OA se complementam para formar um leque de características que o definem.

A interoperabilidade, que permite a utilização dos $\mathrm{OA}$ em diferentes plataformas e sistemas, também é um dos benefícios da utilização de um padrão de metadados. Conforme Behar et al., esta característica "[...] potencializa a reutilização dos objetos, na medida em que visa à articulação/comunicação de materiais diferentes, plataformas e ferramentas" (BEHAR, 2009, p. 68). A interoperabilidade está relacionada ao conceito de padronização dos metadados e da linguagem de programação das tecnologias instrucionais orientadas a objetos. De acordo com Tarouco, Fabre, Tamusiunas (2003, p. 2) a interoperabilidade possibilita a "utilização de componentes desenvolvidos em um local, com algum conjunto de ferramentas ou plataformas, em outros locais com outras ferramentas e plataformas".

A característica dos OA poderem ser utilizados independentes da sua base tecnológica de origem, sem reprojeto ou recodificação, chama-se durabilidade (TAROUCO, FABRE e TAMUSIUNAS, 2003). Está relacionada, como o próprio nome dá a entender, a permanência do OA, sua duração independente de mudança tecnológica sem a necessidade de se refazer o seu design ou a sua configuração. Manter um objeto de aprendizagem em uso, ou qualquer recurso tecnológico é um desafio, pois se sabe da constante evolução das tecnologias de informação e comunicação. Por isso, mais uma vez, torna-se necessário o esforço conjunto das instituições interessadas na manutenção dos objetos de aprendizagem. Portanto, de acordo com as suas características, os $\mathrm{OA}$ podem ser incorporados a diferentes atividades pedagógicas, com o objetivo de tornar o conteúdo mais dinâmico e interativo. Assim, este material, quando bem construído não se restringe ao ambiente inicial em que foi formulado. Dependendo do seu uso, OA podem funcionar como poderosos disseminadores de conteúdo, estimulando a produção de conhecimento na forma colaborativa e agregando diferentes percepções relacionadas ao mesmo conteúdo, o que contribui para a evolução desses instrumentos pedagógicos.

A fim de cumprir a função de ampliar e difundir o conteúdo pedagógico numa interface virtual, os objetos de aprendizagem quando construídos devem, conforme mencionado anteriormente, seguir padrões de metadados que servirão de orientação para o seu armazenamento em repositórios digitais. Os repositórios de OA funcionam como bibliotecas virtuais, nas quais o material digital fica armazenado e é catalogado e indexado de acordo com as informações disponibilizadas pelo seu autor. Quanto maior a qualidade dos dados fornecidos aos repositórios, maior será a sua capacidade de posterior recuperação. O objetivo destas bases de dados é reunir e permitir a pesquisa de objetos de aprendizagem, de acordo com filtros de busca relacionados a cada tipo de repositório.

O armazenamento de objetos de aprendizagem em repositórios digitais é a última ação da elaboração, tendo em vista a possibilidade de reutilização e disponibilidade deste material digital pedagógico. Os repositórios de OA são importantes ferramentas de pesquisa, tanto para professores que desejam utilizar o material em sala de aula, como para pesquisadores do tema, pois reúnem em uma base de dados os diferentes tipos de objetos e conteúdos já elaborados. 
Através da identificação de conteúdo pelos metadados, impulsionam o uso e associam os objetos de aprendizagem a um local específico e não dispersos na internet. Existem diversos repositórios de objetos de aprendizagem. Cada qual contém normas e padrões determinados pelas empresas ou consórcios que os produziu. Conforme mencionado anteriormente, são exemplos destas bases de dados: MERLOT da California State University; RIVED da Secretaria de Educação à distância; CESTA (Coletânea de Entidades de Suporte ao uso de Tecnologia na Aprendizagem) da Universidade Federal do Rio Grande do Sul ${ }^{6}$; BIOE (Banco Internacional de Objetos de Aprendizagem) ${ }^{7}$ do Ministério da Educação.

\section{Microsoft Onenote bloco de anotações como OA reutilizável}

Através do estudo e da abordagem da literatura, definiu-se objetos de aprendizagem como um dispositivo digital reutilizável, com princípios pedagógicos, voltado para o ensino e para a aprendizagem. Com essa definição em mente, estende-se esta investigação ao campo empírico ao se fazer o estudo de caso do uso do Microsoft OneNote como objeto de aprendizagem.

\subsection{Metodologia}

O objeto de estudo desta investigação observa os OA reutilizáveis. A questão de pesquisa considera como esse objeto pode ser utilizado pelos profissionais do ensino. Para responder a esta questão e ao objetivo de pesquisa que busca definir didaticamente OA para aplicação no ensino, a amostragem considerada é o bloco de notas do Microsoft OneNote. Investiga-se como recorte a aplicação desta ferramenta na disciplina de Design da Informação da Universidade Federal de Pelotas no $1^{\circ}$ semestre de 2016. A investigação aborda a problemática contemporânea em mediações sociais no ensino. Por esse motivo, considera-se que a técnica de estudo de caso é apropriada para compreender a inserção de tecnologias nos processos de aprendizagem. Segundo Yin, "o estudo de caso é uma inquirição empírica que investiga um fenômeno contemporâneo dentro de um contexto da vida real, quando a fronteira entre o fenômeno e o contexto não é claramente evidente e onde múltiplas fontes de evidência são utilizadas" (2001, p. 32). Como ferramenta de pesquisa no estudo, é feita a observação direta no recorte do estudo buscando definir e caracterizar objetos de aprendizagem. Para Duarte "o estudo de caso deve ter preferência quando se pretende examinar eventos contemporâneos, em situações onde não se podem manipular comportamentos relevantes e é possível empregar suas fontes de evidências" (2005, p. 219).

A observação direta é feita a partir do estudo da produção, por parte do professor que aplica o uso do OneNote, e da recepção, por parte dos alunos da turma atendidos através da ferramenta. Em questão está o caso único incorporado de um fenômeno, sendo este único por se tratar de apenas uma aplicação individual do fenômeno e incorporado por analisar o viés do produtor (o professor) e do receptor (os alunos). As categorias de análise seguidas para o presente estudo de caso seguem as características dos objetos de aprendizagem, quais sejam: autonomia, interatividade, acessibilidade, interoperabilidade e durabilidade. Os resultados estão organizados a partir da análise dessas categorias e da própria descrição do objeto.

\subsection{Resultados}

O OneNote é um software da Microsoft que pode ser adquirido a partir de uma assinatura mensal ou ainda pela compra da licença de uso da versão atual, porém há uma versão gratuita para download ou para uso online com alguns recursos limitados. A informação do custo do OneNote e a possibilidade de acesso gratuito merece atenção nesta

\footnotetext{
${ }^{6} \mathrm{http}: / /$ www.cinted.ufrgs.br/CESTA/

${ }^{7} \mathrm{http}: / /$ objetoseducacionais2 .mec.gov.br/
} 
V Congresso Brasileiro de Informática na Educação (CBIE 2016)

Anais do XXII Workshop de Informática na Escola (WIE 2016)

pesquisa visto que se deseja utilizar o aplicativo na definição de objeto de aprendizagem e a primeira questão a ser problematizada é o próprio acesso à ferramenta. Para que o objeto de aprendizagem alcance a amplitude de alunos desejada nas universidades, especialmente as públicas, que é o caso do recorte desta pesquisa, é necessário que o sistema não onere os estudantes para que não se crie restrições financeiras ao acesso do conteúdo do OA.

A ferramenta OneNote permite que o professor crie blocos de anotações que podem servir como complemento de conteúdo às atividades da sala de aula presencial ou virtual, bem como ser utilizada para criação e armazenamento de objetos de aprendizagem. Dessa forma, cada bloco de anotação pode tanto um OA autônomo quanto um repositório de vários objetos de aprendizagem. No bloco de anotações, o professor pode criar 'Grupo de Seções', 'Seções' e 'Páginas' para arquitetar a informação em níveis globais e locais, como pode ser visto no sitemap do bloco de anotações da Disciplina de Design de Informação na Figura 1:

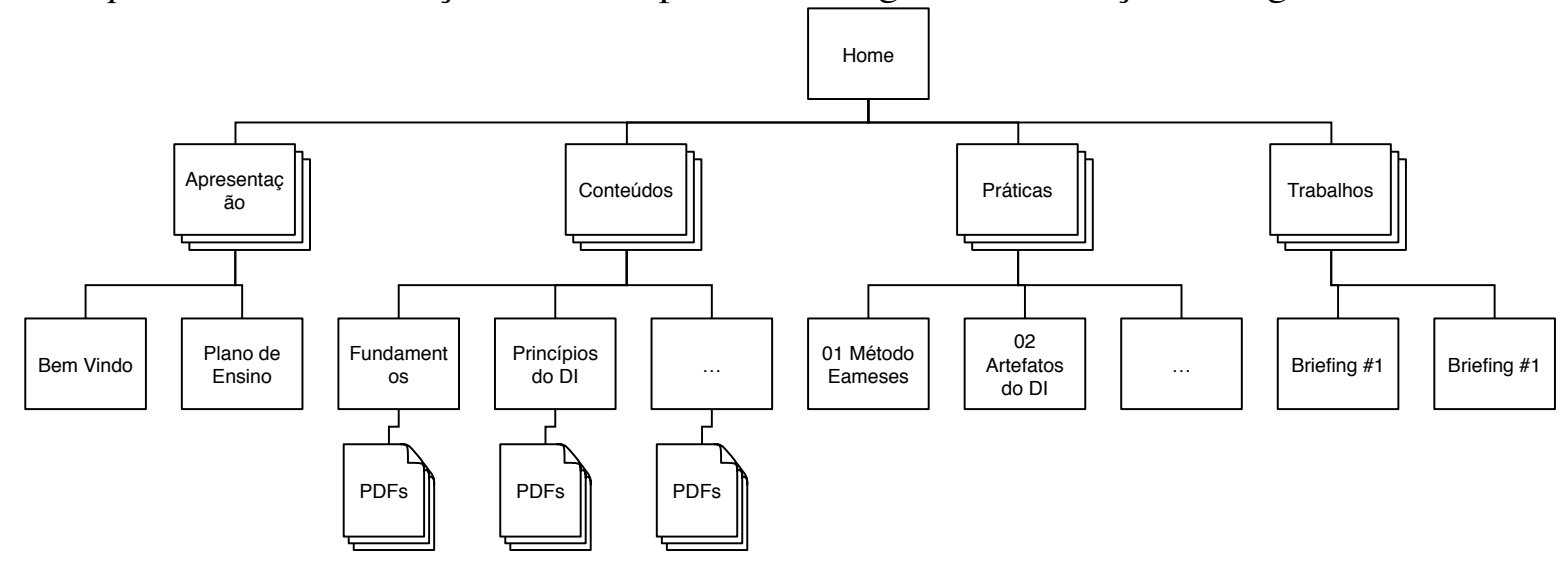

Figura 1 - Sitemap bloco de anotações da Disciplina de Design de Informação

Fonte: Desenvolvido pelo próprio autor baseado na pesquisa elaborada.

A ferramenta possui consistência com relação a outros aplicativos do pacote Office. Isso proporciona mais usabilidade na interação e facilita a produção de conteúdo, já que usuários experientes do Word encontrarão interface semelhante para produzir e publicar conteúdo na web. Observa-se na Figura 2 como o OneNote é semelhante ao Word e ao Excel.

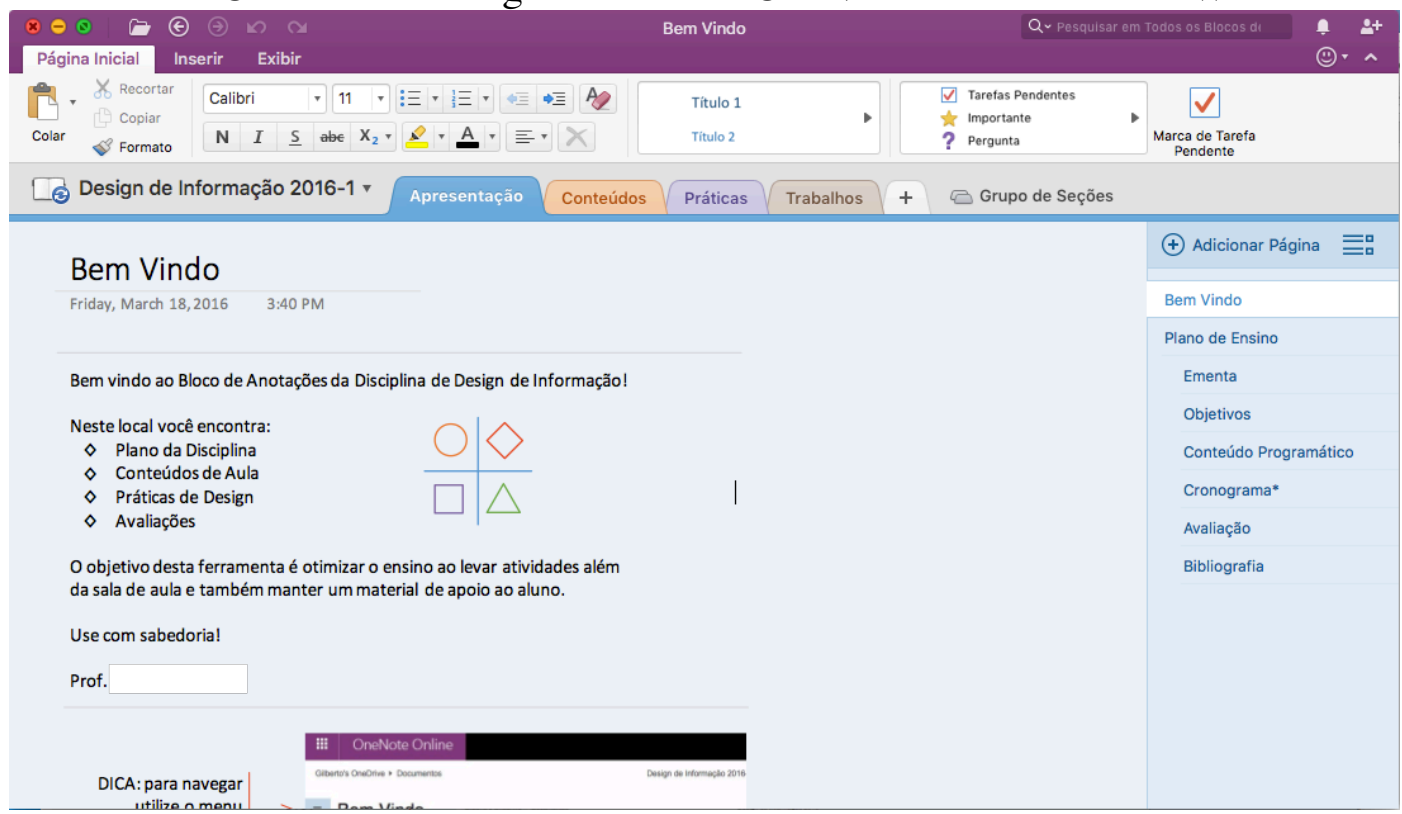

Figura 2 - Interface bloco de anotações da Disciplina de Design de Informação

Fonte: Microsoft OneNote para Mac 2016. 
A partir da ferramenta 'Compartilhar este bloco de anotações' é possível publicar o conteúdo automaticamente em uma página web. O link para compartilhamento é gerado e, ao enviar a $\mathrm{URL}^{8}$ aos estudantes, o acesso ao conteúdo é imediato por qualquer navegador. Como observado no sitemap (Figura 1) e na interface gráfica do usuário (Figura 2), o bloco de anotações pode apresentar conteúdo individual e coerente quando organizado cronologicamente ao respeitar a característica de meio início e fim. Logo, a característica de autonomia dos OAs é cumprida. O fato de ser acessível por qualquer navegador web também corrobora com o conteúdo autônomos, pois está ao alcance do estudante independente da plataforma que utiliza. $\mathrm{O}$ estudante pode acessar ainda o arquivo do bloco de anotações de sua turma diretamente pelo navegador ou baixar a ferramenta. No caso de instalar o OneNote em seu próprio equipamento, torna-se possível editar o arquivo compartilhado e manter anotações sobre o conteúdo sem alterar o arquivo do professor ou dos demais colegas. Essa é uma funcionalidade que atenderá à característica de interatividade dos OAs, ao permitir interação entre usuário e conteúdo.

Quando acessado pelo celular, o usuário precisa ter instalado o aplicativo mobile para o dispositivo, que também possibilita a edição para que o estudante faça suas anotações no próprio arquivo. Com isso, os estudantes têm autonomia em gerenciar os seus conteúdos na própria sala de aula. No caso analisado, o professor compartilha antecipadamente os slides que são estudados em sala de aula. Observa-se a partir dessa prática que os alunos utilizavam seus celulares para anotarem ou acompanharem diretamente o conteúdo previamente estudado a partir das leituras recomendadas. Alguns alunos preferiam imprimir os arquivos PDFs publicados, porém esta prática não é recomendada por não ser sustentável. Indiferente da forma de uso, os estudantes relataram que a prática permite que eles passem mais tempo prestando atenção em sala de aula, já que as anotações são simplificadas, visto que o é apresentado no projetor já está disponível em seus próprios blocos de anotações virtuais.

Como observado, o conteúdo gerado pelo bloco de anotações é multiplataforma e isso permite o uso de ferramentas de acessibilidade disponíveis nos próprios dispositivos dos usuários. O conteúdo textual é todo publicado em formato de texto e não em imagens, o que torna possível a leitura automática do mesmo por meio de ferramentas como o VoiceOver 9 As imagens recebem descrições para que também possam ser compreendidas por ferramentas que tornam o conteúdo mais acessível, cuja característica é importante aos OA.

\section{Conclusão}

Os blocos de anotações do OneNote oferecem a possibilidade de padronização na produção e compartilhamento de conteúdo. No caso investigado, o professor busca por uma padronização na organização do conteúdo publicado para garantir a interoperabilidade em diferentes plataformas, bem como entre diferentes disciplinas. O objetivo do professor é utilizar a ferramenta para todas as suas turmas. Existe ainda a preocupação com a publicação dos dados para atender a característica de durabilidade, pois o mesmo bloco de anotações poderá ser replicado para a mesma disciplina em edições futuras. O OneNote suporta ainda o serviço Sway ${ }^{10}$ para a construção de lições que é facilmente integrado aos blocos de anotações. A partir da plataforma Educator ${ }^{11}$, os professores podem compartilhar lições, cursos completos e experiências. Ao permitir interoperabilidade, interatividade e durabilidade, esta plataforma de colaboração potencializa a expansão dessas características dos objetos de aprendizagem. $\mathrm{O}$

\footnotetext{
${ }^{8}$ A página da disciplina Design de Informação pode ser acessada a partir da url https://onedrive.live. com/redir?page=view\&resid=AC0EBB1C7FB8D6FE!371\&authkey=!ACA5Y6h7hWzoFrA

${ }^{9}$ Para saber mais sobre o VoiceOver do iOS visite a url http://www.apple.com/br/accessibility/ios/voiceover/

${ }^{10}$ Disponível em inglês em https://sway.com/?ui=en-US\&rs=US

${ }^{11}$ Disponível em inglês em https://education.microsoft.com
} 
uso da plataforma associada à ferramenta proporciona aprendizado também ao professor no momento que passa a interagir com outros educadores por meio de lições compartilhadas. Portanto, ao investigar as características dos OA e descrever o caso em questão, atinge-se o objetivo de definir didaticamente objetos de aprendizagem. O uso da ferramenta permite que os estudantes possuam um conteúdo autônomo que colabora com o aprendizado. A partir do estudo de caso da aplicação do OneNote em sala de aula, conclui-se que a ferramenta atende a todas características de objetos de aprendizagem.

\section{Referências}

BEHAR, P. A. Objetos de aprendizagem para educação à distância. In: ARTMED. Modelos pedagógicos em educação à distância. Porto Alegre, 2009. p.66-91.

BEHAR, P. A.; TORRENZZAN, C. A. W .; RÜCKERT, A. B. PEDESINGN: a construção de um objeto de aprendizagem baseado no design pedagógico. RENOTE, v. 6, n. 2, 2008. Disponível em: < http://seer.ufrgs.br/renote/article/view/14404/8309 >. Acesso em: 16 mai. 2016.

CONSONI, G. B. Conversações online nos comentários de blogs: interações dialógicas nos blogs Melhores do Mundo, Interney e Pensar Enlouquece. (Dissertação de Mestrado). PPGCOM, UFRGS, Porto Alegre,2010.

DUARTE, M. Y. M. Estudo de Caso. In: DUARTE, J. e BARROS, A. Métodos e técnicas de pesquisa em comunicação. São Paulo: Atlas, 2005. p. 213-235.

ECO, H. Como se faz uma tese. 14ª . São Paulo: Perspectiva, 1998.

GALAFASSI, F. P.; GLUZ, J. O. C.; GALAFASSI, C. Análise Crítica das Pesquisas Recentes sobre as Tecnologias de Objetos de Aprendizagem e Ambientes Virtuais de Aprendizagem. Revista Brasileira de Informática na Educação (RBIE), v. 21, n. 3, 2013. Disponível em: < http://www.br-ie.org/pub/index.php/rbie/article/view/2351/2457 >. Acesso em: 13 jun. 2016.

PEREIRA, M. L. A.; PORTO, F. A. M.; MELO, R. N. Objetos de aprendizagem reutilizáveis (RLOs): conceitos, padronização, uso e armazenamento. (Monografia em Ciência da Computação). Departamento de Informática, PUC-Rio2003.

POLSANI, P. R. Use and abuse of reusable learning objects. Journal of Digital Information, v. 3, n. 4, 2003.

PRATA, C. L.; NASCIMENTO, A. C. A.; PIETROCOLA, M. Políticas para fomento de produção e uso de objetos de aprendizagem. In. Objetos de aprendizagem: uma proposta de recurso pedagógico. Brasília: SEED, 2007. p.107-121.

REDE INTERATIVA VIRTUAL DE EDUCAÇÃO. Conheça o Rived. 2011. Disponível em: $<$ http://rived.mec.gov.br/site_objeto_lis.php >. Acesso em: 16 mai. 2016.

TAROUCO, L. M. R.; FABRE, M.-C. J. M.; TAMUSIUNAS, F. R. Reusabilidade de objetos educacionais. RENOTE, v. 1, n. 1, fev. 2003. Disponível em: < http://seer.ufrgs.br/renote/article/view/13628/7697 >. Acesso em: 16 mai. 2016.

WILEY, D. A. Connecting learning objects to instructional design theory: a definition, a metaphor, and a taxonomy. In. The Instructional Use of Learning Objects, 2000. p.1-35. Disponível em: < http://reusability.org/read/chapters/wiley.doc >. Acesso em: 16 mai. 2016.

YIN, R. K. Estudo de Caso: planejamento e métodos. 2a ed. Porto Alegre: Bookman, 2001. 